Article

\title{
Temperature-Controlled Assembly/Reassembly of Two Dicarboxylate-Based Three-Dimensional Co(II) Coordination Polymers with an Antiferromagnetic Metallic Layer and a Ferromagnetic Metallic Chain
}

\author{
Hui-Chen Yu, Chin-Hsuan Lin and Chen-I Yang * \\ Department of Chemistry, Tunghai University, Taichung 407, Taiwan; a010406@yahoo.com.tw (H.-C.Y.); \\ az74410a@gmail.com (C.-H.L.) \\ * Correspondence: ciyang@thu.edu.tw; Tel.: +886-4-2359-0121 (ext. 32237)
}

Received: 13 April 2019; Accepted: 30 April 2019; Published: 2 May 2019

\begin{abstract}
Two new dicarboxylate-based three-dimensional cobalt coordination polymers, $\left[\mathrm{Co}\left(\mathrm{Me}_{2} \mathrm{mal}\right)(\mathrm{bpe})_{0.5}\left(\mathrm{H}_{2} \mathrm{O}\right)\right]_{n} \quad(\mathbf{1})$ and $\left[\mathrm{Co}\left(\mathrm{Me}_{2} \mathrm{mal}\right)(\mathrm{bpe})_{0.5}\right]_{n} \quad$ (2), were synthesized from dimethylmalonic acid $\left(\mathrm{H}_{2}-\mathrm{Me}_{2} \mathrm{mal}\right)$ in temperature-controlled solvothermal reactions. Lower temperatures $\left(60-80^{\circ} \mathrm{C}\right)$ favored the formation of $\mathbf{1}$, while higher temperatures $\left(120^{\circ} \mathrm{C}\right)$ favored the production of $\mathbf{2}$. Compound $\mathbf{1}$ is comprised of $\mathrm{Co}$ (II) corrugated layers linked by syn-anti carboxylate bridges from the $\mathrm{Me}_{2} \mathrm{mal}^{2-}$ ligands and pillared through bis-monodentate bpe groups. Compound 2 is comprised of a three-dimensional network involving one-dimensional Co-carboxylate chains bonded by antisymmetric $\mu_{4}-\mathrm{Me}_{2} \mathrm{mal}^{2-}$ ligands and aligned parallel to the [001] direction. The solvothermal retreatment of crystalline samples of 1 in a DMF/ $\mathrm{H}_{2} \mathrm{O}$ solvent at $120^{\circ} \mathrm{C}$ allowed the structural reassembly, with complete conversion within 2 over $48 \mathrm{~h}$. Magnetic analyses revealed that compound 1 exhibits both spin-orbital coupling and antiferromagnetic interactions through a syn-anti carboxylate $\left(\mathrm{Me}_{2} \mathrm{mal}^{2-}\right)$ bridge exchange pathway [Co-Co separation of $\left.5.478 \AA\right]$ ] and compound 2 showed a ferromagnetic interaction resulting from the short $\mathrm{Co}-\mathrm{Co}$ separation $(3.150 \AA)$ and the small Co-O-Co bridging angles $\left(98.5^{\circ}\right.$ and $\left.95.3^{\circ}\right)$ exchange pathway which was provided by $\mu_{4}-\mathrm{Me}_{2} \mathrm{mal}^{2-}$ bridging ligand.
\end{abstract}

Keywords: assembly/reassembly; coordination polymer; magnetic properties; antiferromagnetic; ferromagnetic

\section{Introduction}

Coordination polymers (CPs), hybrid crystalline materials comprised of organic and inorganic components whose structures are extended by coordination bonds, have attracted considerable interest in the field of condensed matter [1-10]. The beneficial features of these materials are attributed to the building blocks from which they are constructed, which have of both organic and inorganic parts, thus conferring hybrid properties. Consequently, they commonly possess novel and fascinating properties or functionalities, which originate from the hybridization of the inorganic-organic parts. Although CPs can have many other potentials and fascinating properties, including heterogeneous catalysis, gas storage, gas separation, and drug carriers [11-18], magnetism is also an important area of interest [19-29]. This is particularly true, when the paramagnetic metal centers are bridged by short ligands (such as azido anion, cyanide, and carboxylate groups) to produce extended structures, 1D chains, and 2D layers, which is the structural basis for transmitting significant magnetic interactions between spin carriers and the metal ions [30-32]. One main benefit of magnetic coordination polymers (MCPs) is they provide the possibility and opportunity for tuning the nature of magnetic interactions within the 
materials [33-36]. Magnetically coupled interactions, ferromagnetic (FO), or antiferromagnetic (AF), depend on the types of spin carriers and a detailed understanding of the coupling pathway between them. The system and topology of magnetic interactions through space can be further adjusted if the starting metal centers, short bridging ligands, building blocks, co-ligands, templates, and related structures are carefully selected and accurately assembled into CPs [37-39].

Moreover, some MCPs can exist in bistable states, which could result in their structures being altered in response to external stimulation such as exchanging counterions, guest molecules, an electric field, or pressure. While in this dynamic structural transformation, their magnetic properties may obviously change. It is well-known that structural transformations can be observed in single-crystal-to-single-crystal transformations [40-44], as well as in crystal reassembly [35]. It follows that studies of magnetic materials and structural transformations of network materials could open opportunities for gaining an improved understanding of the essential characteristics that affect crystal nucleation and growth and thus would be of benefit for exploiting multi-functional materials.

One of the important characteristics for a polycarboxylate bridging ligand with metal centers is that they can give rise to a wide variety of multinuclear cluster-based compounds ranging from discrete units to multidimensional systems. Dimethylmalonic acid $\left(\mathrm{H}_{2}-\mathrm{Me}_{2} \mathrm{mal}\right)$ is one such potential candidate for the synthesis of CPs with diverting magnetic behaviors, such as ferromagnetism and magnetic ordering, because they not only link the metal centers to the multi-dimensional network but also reduce the distance between the metal centers, which would lead to a significant magnetic interaction.

In attempt to control reaction temperatures in solvothermal processes, we report herein on the synthesis of two $\mathrm{Co}(\mathrm{II})$ coordination polymers, $\left[\mathrm{Co}\left(\mathrm{Me}_{2} \mathrm{mal}\right)(\mathrm{bpe})_{0.5}\left(\mathrm{H}_{2} \mathrm{O}\right)\right]_{n}$ (1) and [Co(Me $\mathrm{Me}_{2} \mathrm{mal}$ (bpe $\left.)_{0.5}\right]_{n}$ (2), from the self-assembly of $\mathrm{H}_{2}-\mathrm{Me}_{2}$ mal and trans-1,2-bis(4-pyridyl)ethylene (bpe) in $\mathrm{DMF} / \mathrm{H}_{2} \mathrm{O}$. The temperature-induced network reassembly from compound $\mathbf{1}$ to compound $\mathbf{2}$ was also observed. Magnetic studies showed that complex $\mathbf{1}$ exhibits both spin-orbital coupling and antiferromagnetic interactions through the syn-anti carboxylate $\left(\mathrm{Me}_{2} \mathrm{mal}^{2-}\right)$ bridge exchange pathway with a long Co-Co separation. In contrast, complex 2 shows a ferromagnetic interaction that occurs by an exchange pathway with a short Co-Co separation ( $3.150 \AA$ ) and small $\mathrm{Co}-\mathrm{O}-\mathrm{Co}$ bridging angles $\left(98.5^{\circ}\right.$ and $\left.95.3^{\circ}\right)$ provided by the antisymmetric $\mu_{4}-\mathrm{Me}_{2} \mathrm{mal}^{2-}$ bridging ligand.

\section{Experimental}

\subsection{Materials and Methods}

All reagents and solvents were used as received without further purification, and aerobic conditions were performed for all reactions.

\subsection{The Synthesis of $\left[\mathrm{Co}\left(\mathrm{Me}_{2} \text { mal }\right)(\text { bpe })_{0.5}\left(\mathrm{H}_{2} \mathrm{O}\right)\right]_{n} \mathbf{( 1 )}$}

A mixture of the solution of $\mathrm{Co}\left(\mathrm{CH}_{3} \mathrm{COO}\right)_{2} \cdot 4 \mathrm{H}_{2} \mathrm{O}(12.5 \mathrm{mg}, 0.05 \mathrm{mmol}), \mathrm{H}_{2}-\mathrm{Me}_{2} \mathrm{mal}(6.6 \mathrm{mg}, 0.05$ $\mathrm{mmol})$, bpe $(9.1 \mathrm{mg}, 0.05 \mathrm{mmol})$ and $\mathrm{DMF} / \mathrm{H}_{2} \mathrm{O}(1 \mathrm{~mL} / 5 \mathrm{~mL})$ was heated at $80^{\circ} \mathrm{C}$ for two days. After the mixtures were slowly cooled to room temperature, purple crystals of compound 1 suitable for single crystal X-ray analysis were obtained. The purple crystals were washed with water and collected by suction filtration. The simulated powder X-ray diffraction pattern from the single-crystal data was compared well with the pattern of the bulk sample (vide infra). The yield was $41 \%$ based on Co. Elemental analysis calcd (\%) for $\mathrm{C}_{11} \mathrm{H}_{13} \mathrm{CoNO}_{5}$ (1): $\mathrm{C}, 44.27 ; \mathrm{H}, 4.36 ; \mathrm{N}, 4.70$. Found: $\mathrm{C}, 44.23 ; \mathrm{H}, 4.18$; $\mathrm{N}, 4.60$. IR data (KBr disk, $\left.\mathrm{cm}^{-1}\right): 3420$ (s), $2979(\mathrm{~m}), 2931$ (w), 1610 (vs), 1534 (vs), 1460 (m), 1428 (s), $1376(\mathrm{~m}), 1350(\mathrm{w}), 1254(\mathrm{w}), 1219(\mathrm{w}), 1192(\mathrm{w}), 1101(\mathrm{w}), 1071(\mathrm{w}), 1015(\mathrm{~m}), 977(\mathrm{w}), 911(\mathrm{w}), 846(\mathrm{~m})$, $832(\mathrm{~m}), 791(\mathrm{~m}), 742(\mathrm{~m}), 688(\mathrm{w}), 603(\mathrm{w}), 553(\mathrm{~m})$.

\subsection{The Synthesis of $\left[\mathrm{Co}\left(\mathrm{Me}_{2} \mathrm{mal}\right)(\mathrm{bpe})_{0.5}\right]_{n}$ (2)}

Method A: $\mathrm{Co}\left(\mathrm{CH}_{3} \mathrm{COO}\right)_{2} \cdot 4 \mathrm{H}_{2} \mathrm{O}(12.5 \mathrm{mg}, 0.05 \mathrm{mmol}), \mathrm{H}_{2}-\mathrm{Me}_{2} \mathrm{mal}(6.8 \mathrm{mg}, 0.11 \mathrm{mmol})$, dpe $(9.1 \mathrm{mg}, 0.05 \mathrm{mmol})$ and $\mathrm{DMF} / \mathrm{H}_{2} \mathrm{O}(1 \mathrm{~mL} / 5 \mathrm{~mL})$ were mixed and placed in a Teflon reactor $(25 \mathrm{~mL})$. 
This mixture was heated to $120^{\circ} \mathrm{C}$ at the heating rate of $14.3^{\circ} \mathrm{C} / \mathrm{h}$, holding at $120^{\circ} \mathrm{C}$ for $48 \mathrm{~h}$, and then cooling to $30^{\circ} \mathrm{C}$ at a rate of $1{ }^{\circ} \mathrm{C} / \mathrm{h}$. The red crystals of compound 2 suitable for single-crystal $\mathrm{X}$-ray analysis were obtained. The crystals were washed a few times with water, collected by suction filtration and dried in air. The yield was 34\% (based on Co). The simulated powder X-ray diffraction pattern from the single-crystal data was compared well with the pattern of the bulk sample (vide infra). Elemental analysis calcd (\%) for $\mathrm{C}_{11} \mathrm{H}_{11} \mathrm{CoNO}_{4}(2)$ : C, 47.12; H, 3.93; N, 5.00. Found: C, 47.25; H, 3.60; N, 5.04. IR data (KBr disk, $\left.\mathrm{cm}^{-1}\right)$ : $3452(\mathrm{~s}), 3071(\mathrm{~m}), 2987(\mathrm{~m}), 2957(\mathrm{~m}), 2939(\mathrm{~m}), 2864(\mathrm{~m}), 1656(\mathrm{vs})$, 1612 (vs), 1575 (vs), 1466 (m), 1433 (m), 1394 (vs), 1369 (s), 1345 (s), 1276 (s), 1196 (m), 1096 (w), 1078 $(\mathrm{w}), 1022(\mathrm{~m}), 985(\mathrm{~m}), 961(\mathrm{w}), 940(\mathrm{w}), 893(\mathrm{~m}), 828(\mathrm{~m}), 794(\mathrm{w}), 758(\mathrm{w}), 701(\mathrm{~m}), 596(\mathrm{~m}), 551(\mathrm{~m})$, $529(\mathrm{w}), 472(\mathrm{w})$.

Method B: The crystalline samples of $1(50.0 \mathrm{mg}, 0.17 \mathrm{mmol})$ and $\mathrm{DMF} / \mathrm{H}_{2} \mathrm{O}(1 \mathrm{~mL} / 5 \mathrm{~mL})$ were placed in a Teflon reactor $(25 \mathrm{~mL})$. The reactor was then heated to $120^{\circ} \mathrm{C}$ at the heating rate of $14.3^{\circ} \mathrm{C} / \mathrm{h}$, holding at $120^{\circ} \mathrm{C}$ for $48 \mathrm{~h}$, and then cooling to $30^{\circ} \mathrm{C}$ at a rate of $1{ }^{\circ} \mathrm{C} / \mathrm{h}$. The red crystals were obtained, washed by water, dried in air, and collected by filtration. The yield was $77 \%$ ( $36.1 \mathrm{mg}$ ). The IR spectrum and powder $\mathrm{X}$-ray diffraction pattern were identical to that of 2 prepared by method A. The elemental analysis calcd (\%) for $\mathrm{C}_{11} \mathrm{H}_{11} \mathrm{CoNO}_{4}(2)$ : $\mathrm{C}, 47.12 ; \mathrm{H}, 3.93 ; \mathrm{N}, 5.00$. Found: $\mathrm{C}, 47.18 ; \mathrm{H}, 3.69 ; \mathrm{N}, 4.98$.

\subsection{X-ray Crystallography}

For compounds $\mathbf{1}$ and $\mathbf{2}$, the diffraction intensity data were collected at $150 \mathrm{~K}$ on a Bruker APEXII CCD diffractometer (Bruker, Karlsruhe, Germany) with graphite-monochromated Mo K $\alpha$ radiation $(\lambda=0.7107 \AA)$. The program SADABS (Bruker, 2016) was used for absorption corrections [45]. Direct methods were used to solve the structure, and the SHELX2014 program [46] was used to refine the structure with the full-matrix least-squares method against $\mathrm{F}^{2}$. All non-hydrogen atoms were refined anisotropic thermal parameters, whereas the hydrogen atoms on their respective carbon atoms were placed in ideal, calculated positions, using the riding model with isotropic thermal parameters. For compounds $\mathbf{1}$ and 2, the experimental details for X-ray crystallographic data, and the refinements are summarized in Table 1, and the selected bond distances and angles are listed in Tables 2 and 3.

Table 1. The Crystallographic data for compounds $\mathbf{1}$ and 2.

\begin{tabular}{|c|c|c|}
\hline Compound & 1 & 2 \\
\hline Formula & $\mathrm{C}_{11} \mathrm{H}_{13} \mathrm{CoNO}_{5}$ & $\mathrm{C}_{11} \mathrm{H}_{11} \mathrm{CoNO}_{4}$ \\
\hline $\mathrm{FW}_{\mathrm{W}}$ & 298.15 & 280.14 \\
\hline Crystal system & Monoclinic & Monoclinic \\
\hline Space group & $P 2_{1} / \mathrm{n}$ & $P 2 / \mathrm{c}$ \\
\hline $\mathrm{a} / \AA$ & $7.4005(18)$ & $9.352(4)$ \\
\hline $\mathrm{b} / \AA$ & $21.647(5)$ & $12.278(5)$ \\
\hline$c / \AA$ & 7.4050(19) & $9.880(4)$ \\
\hline$\alpha /^{\circ}$ & 90 & 90 \\
\hline$\beta /{ }^{\circ}$ & $92.473(5)$ & $93.296(7)$ \\
\hline$\gamma /{ }^{\circ}$ & 90 & 90 \\
\hline $\mathrm{V} / \AA^{3}$ & $1185.2(5)$ & $1132.6(8)$ \\
\hline Z & 4 & 4 \\
\hline $\mathrm{T} / \mathrm{K}$ & $150(2)$ & $150(2)$ \\
\hline$D_{\mathrm{c}} / \mathrm{g} \mathrm{cm}^{-3}$ & 1.671 & 1.643 \\
\hline$\mu / \mathrm{mm}^{-1}$ & 1.460 & 1.516 \\
\hline$(\Delta \rho) \max , \min / \mathrm{e} \AA^{-3}$ & $0.400,-0.393$ & $0.602,-0.552$ \\
\hline Measured/independent (Rint) reflections & $8905 / 2832(0.0602)$ & $7570 / 2549(0.0577)$ \\
\hline Observed reflections $[I>2 \sigma(I)]$ & 2832 & 2549 \\
\hline Goodness-of-fits on $F^{2}$ & 1.009 & 1.000 \\
\hline$R_{1}^{1}, \mathrm{w} R_{2}^{2}$ (all data) & $0.0636,0.0870$ & $0.0584,0.0976$ \\
\hline$R_{1}^{1}, \mathrm{w} R_{2}^{2}(\mathrm{I}>2 \sigma(\mathrm{I}))$ & $0.0396,0.0775$ & $0.0386,0.0897$ \\
\hline
\end{tabular}


Table 2. Selected bond distances $(\AA)$ and angles $\left(^{\circ}\right)$ for compound 1.

\begin{tabular}{cccc}
\hline \multicolumn{4}{c}{ Compound 1 } \\
\hline $\mathrm{Co}(1)-\mathrm{O}(2)$ & $2.0747(18)$ & $\mathrm{Co}(1)-\mathrm{O}(4)$ & $2.1147(19)$ \\
$\mathrm{Co}(1)-\mathrm{O}(1)$ & $2.0984(19)$ & $\mathrm{Co}(1)-\mathrm{O}(6)$ & $2.1247(19)$ \\
$\mathrm{Co}(1)-\mathrm{O}(3)$ & $2.1026(18)$ & $\mathrm{Co}(1)-\mathrm{N}(1)$ & $2.151(2)$ \\
$\mathrm{O}(2)-\mathrm{Co}(1)-\mathrm{O}(1)$ & $170.43(7)$ & $\mathrm{O}(3)-\mathrm{Co}(1)-\mathrm{O}(6)$ & $96.72(8)$ \\
$\mathrm{O}(2)-\mathrm{Co}(1)-\mathrm{O}(3)$ & $84.76(7)$ & $\mathrm{O}(4)-\mathrm{Co}(1)-\mathrm{O}(6)$ & $86.47(8)$ \\
$\mathrm{O}(1)-\mathrm{Co}(1)-\mathrm{O}(3)$ & $87.53(7)$ & $\mathrm{O}(2)-\mathrm{Co}(1)-\mathrm{N}(1)$ & $88.50(8)$ \\
$\mathrm{O}(2)-\mathrm{Co}(1)-\mathrm{O}(4)$ & $89.85(7)$ & $\mathrm{O}(1)-\mathrm{Co}(1)-\mathrm{N}(1)$ & $86.03(8)$ \\
$\mathrm{O}(1)-\mathrm{Co}(1)-\mathrm{O}(4)$ & $97.55(7)$ & $\mathrm{O}(3)-\mathrm{Co}(1)-\mathrm{N}(1)$ & $91.42(8)$ \\
$\mathrm{O}(3)-\mathrm{Co}(1)-\mathrm{O}(4)$ & $173.96(8)$ & $\mathrm{O}(4)-\mathrm{Co}(1)-\mathrm{N}(1)$ & $85.69(8)$ \\
$\mathrm{O}(2)-\mathrm{Co}(1)-\mathrm{O}(6)$ & $95.11(7)$ & $\mathrm{O}(6)-\mathrm{Co}(1)-\mathrm{N}(1)$ & $171.36(8)$ \\
$\mathrm{O}(1)-\mathrm{Co}(1)-\mathrm{O}(6)$ & $91.41(8)$ & & \\
\hline
\end{tabular}

Table 3. Selected bond distances $(\AA)$ and angles $\left(^{\circ}\right)$ for compound 2.

\begin{tabular}{cccc}
\hline \multicolumn{3}{c}{ Compound 2 } \\
\hline $\mathrm{Co}(1)-\mathrm{N}(1)$ & $2.067(2)$ & $\mathrm{Co}(2)-\mathrm{O}(3)$ & $1.9919(19)$ \\
$\mathrm{Co}(1)-\mathrm{N}(1) \# 1$ & $2.068(2)$ & $\mathrm{Co}(2)-\mathrm{O}(3) \# 2$ & $1.9919(19)$ \\
$\mathrm{Co}(1)-\mathrm{O}(1) \# 1$ & $2.145(2)$ & $\mathrm{Co}(2)-\mathrm{O}(2) \# 2$ & $2.104(2)$ \\
$\mathrm{Co}(1)-\mathrm{O}(1)$ & $2.145(2)$ & $\mathrm{Co}(2)-\mathrm{O}(2)$ & $2.104(2)$ \\
$\mathrm{Co}(1)-\mathrm{O}(3) \# 1$ & $2.163(2)$ & $\mathrm{Co}(2)-\mathrm{O}(1)$ & $2.1164(19)$ \\
$\mathrm{Co}(1)-\mathrm{O}(3)$ & $2.163(2)$ & $\mathrm{Co}(2)-\mathrm{O}(1) \# 2$ & $2.1164(19)$ \\
$\mathrm{N}(1)-\mathrm{Co}(1)-\mathrm{N}(1) \# 1$ & $98.11(14)$ & $\mathrm{O}(3)-\mathrm{Co}(2)-\mathrm{O}(3) \# 2$ & 180.0 \\
$\mathrm{~N}(1)-\mathrm{Co}(1)-\mathrm{O}(1) \# 1$ & $90.27(9)$ & $\mathrm{O}(3)-\mathrm{Co}(2)-\mathrm{O}(2) \# 2$ & $88.90(8)$ \\
$\mathrm{N}(1) \# 1-\mathrm{Co}(1)-\mathrm{O}(1) \# 1$ & $171.61(8)$ & $\mathrm{O}(3) \# 2-\mathrm{Co}(2)-\mathrm{O}(2) \# 2$ & $91.10(8)$ \\
$\mathrm{N}(1)-\mathrm{Co}(1)-\mathrm{O}(1)$ & $171.60(9)$ & $\mathrm{O}(3)-\mathrm{Co}(2)-\mathrm{O}(2)$ & $91.10(8)$ \\
$\mathrm{N}(1) \# 1-\mathrm{Co}(1)-\mathrm{O}(1)$ & $90.27(9)$ & $\mathrm{O}(3) \# 2-\mathrm{Co}(2)-\mathrm{O}(2)$ & $88.90(8)$ \\
$\mathrm{O}(1) \# 1-\mathrm{Co}(1)-\mathrm{O}(1)$ & $81.35(11)$ & $\mathrm{O}(2) \# 2-\mathrm{Co}(2)-\mathrm{O}(2)$ & 180.0 \\
$\mathrm{~N}(1)-\mathrm{Co}(1)-\mathrm{O}(3) \# 1$ & $88.63(9)$ & $\mathrm{O}(3)-\mathrm{Co}(2)-\mathrm{O}(1)$ & $84.56(7)$ \\
$\mathrm{N}(1) \# 1-\mathrm{Co}(1)-\mathrm{O}(3) \# 1$ & $99.80(9)$ & $\mathrm{O}(3) \# 2-\mathrm{Co}(2)-\mathrm{O}(1)$ & $95.45(7)$ \\
$\mathrm{O}(1) \# 1-\mathrm{Co}(1)-\mathrm{O}(3) \# 1$ & $79.86(7)$ & $\mathrm{O}(2) \# 2-\mathrm{Co}(2)-\mathrm{O}(1)$ & $97.78(8)$ \\
$\mathrm{O}(1)-\mathrm{Co}(1)-\mathrm{O}(3) \# 1$ & $90.37(7)$ & $\mathrm{O}(2)-\mathrm{Co}(2)-\mathrm{O}(1)$ & $82.22(8)$ \\
$\mathrm{N}(1)-\mathrm{Co}(1)-\mathrm{O}(3)$ & $99.80(9)$ & $\mathrm{O}(3)-\mathrm{Co}(2)-\mathrm{O}(1) \# 2$ & $95.45(7)$ \\
$\mathrm{N}(1) \# 1-\mathrm{Co}(1)-\mathrm{O}(3)$ & $88.63(9)$ & $\mathrm{O}(3) \# 2-\mathrm{Co}(2)-\mathrm{O}(1) \# 2$ & $84.55(7)$ \\
$\mathrm{O}(1) \# 1-\mathrm{Co}(1)-\mathrm{O}(3)$ & $90.37(7)$ & $\mathrm{O}(2) \# 2-\mathrm{Co}(2)-\mathrm{O}(1) \# 2$ & $82.22(8)$ \\
$\mathrm{O}(1)-\mathrm{Co}(1)-\mathrm{O}(3)$ & $79.86(7)$ & $\mathrm{O}(2)-\mathrm{Co}(2)-\mathrm{O}(1) \# 2$ & $97.78(8)$ \\
$\mathrm{O}(3) \# 1-\mathrm{Co}(1)-\mathrm{O}(3)$ & $167.17(10)$ & $\mathrm{O}(1)-\mathrm{Co}(2)-\mathrm{O}(1) \# 2$ & 180.0 \\
$\mathrm{Co}(2)-\mathrm{O}(3)-\mathrm{Co}(1)$ & $98.52(8)$ & $\mathrm{Co}(2)-\mathrm{O}(1)-\mathrm{Co}(1)$ & $95.34(8)$ \\
\hline
\end{tabular}

Symmetry transformations used to generate equivalent atoms: \#1: $-x+1, y,-z+3 / 2 ; \# 2:-x+1,-y+1,-z+2$; \#3: $-x,-y+2,-z+1$.

\subsection{Physical Measurements}

The temperature dependence (dc) of the magnetic susceptibility measurements for compounds $\mathbf{1}$ and $\mathbf{2}$ were performed on microcrystalline samples, which were restrained in eicosane to prevent torquing, on a Quantum Design MPMS-7 SQUID (Quantum Design, San Diego, CA, USA) equipped with 7.0 T magnets and operated in the range of 2.0-300.0 K. The Pascal's constants [47] were used to estimate the diamagnetic corrections of both compounds from the experimental magnetic susceptibilities to achieve the molar paramagnetic susceptibilities. Elemental analysis (carbon, hydrogen, and nitrogen) of compounds 1 and $\mathbf{2}$ were made using an Elemental vario EL III analyzer (PerkinElmer, Taipei, Taiwan). Thermogravimetric (TG) analyses of both compounds were collected using a Seiko Instrumental, Inc., (Chiba shi, Japan) EXSTAR $6200 \mathrm{TG} / \mathrm{DTA}$ analyzer, operating under a $5^{\circ} \mathrm{C} / \mathrm{min}$ heating rate and a nitrogen atmosphere. Powder X-ray diffraction data were collected using a Rigaku MiniFlex-II X-Ray diffractometer (Tokyo, Japan), operating on a step mode, with a step size of $0.02^{\circ}$ in $\theta$ and a fixed time of $10 \mathrm{~s}$ at $40 \mathrm{kV}, 30 \mathrm{~mA}$ for $\mathrm{Cu}-\mathrm{K} \alpha(\lambda=1.5406 \AA)$. A Perkin-Elmer Spectrum RX1 FTIR spectrometer 
was used to collect the Fourier transform infrared (FTIR) spectra for both compounds (PerkinElmer, Taipei, Taiwan).

\section{Results and Discussion}

\subsection{Synthesis and Characterization of Compounds $\mathbf{1}$ and $\mathbf{2}$}

Compounds 1 and 2 were prepared via self-assembly processes by solvothermal reactions at different temperatures. The reaction of $\mathrm{Co}(\mathrm{OAc})_{2} \cdot 4 \mathrm{H}_{2} \mathrm{O}(0.05 \mathrm{mmol})$ with $\mathrm{H}_{2}-\mathrm{Me}_{2}$ mal $(0.05 \mathrm{mmol})$ and bpe $(0.05 \mathrm{mmol})$ in a $\mathrm{DMF} / \mathrm{H}_{2} \mathrm{O}(1 \mathrm{~mL} / 5 \mathrm{~mL})$ mixed solution at 60 or $80{ }^{\circ} \mathrm{C}$ for $48 \mathrm{~h}$ yielded needle-shaped purple crystals of 1 . No crystals of 1 were formed when the reaction was carried out at room temperature. When the above reaction was performed at $120^{\circ} \mathrm{C}$ for $48 \mathrm{~h}$, however, red crystals of thermodynamically stable products of compound 2 were obtained. When crystals of 1 in the same solvent system were allowed to stand at $120^{\circ} \mathrm{C}$ for about $48 \mathrm{~h}$, the purple colored crystals of 1 were converted into red colored crystals of 2 , thus confirming that crystal reassembly has occurred. The synthesis and structural conversion of 1 to 2 are depicted in Scheme 1. However, except for 1, no new product was formed, as determined by the PXRD patterns, but if the reaction was carried out in the absence of $\mathrm{H}_{2} \mathrm{O} / \mathrm{DMF}$ as the solvent, this indicated that reassembly from 1 to 2 would be simultaneously assisted by both thermal and solvent factors. In viewing the crystal structures of $\mathbf{1}$ and $\mathbf{2}$, the removal of coordinated water from the $\mathrm{Co}(\mathrm{II})$ center and the rearrangement of the carboxylate of $\mathrm{Me}_{2} \mathrm{mal}^{2-}$ and bpe ligands would be expected to take place during the structural conversion process. We assume that the solvent molecules would provide intermolecular interactions, i.e., hydrogen bonding interactions that would be expected to stabilize the structure in the intermediate state and would benefit from the removal of the coordinated water molecules. Such solvent assisted structural transformations have been reported in the literature [48-51], and these findings can be compared to the reassembly of crystals from 1 to 2 . In the reported literature, supramolecular interactions, such as layer-guest-layer hydrogen bonding interactions, stabilize the layer structure. As the temperature increased, the guest water molecules were removed and the structure was induced to transform into a 3D network. We, therefore, assume that the removal of coordination water molecules in $\mathbf{1}$ would be an important factor for the crystal reassembly to 2 .

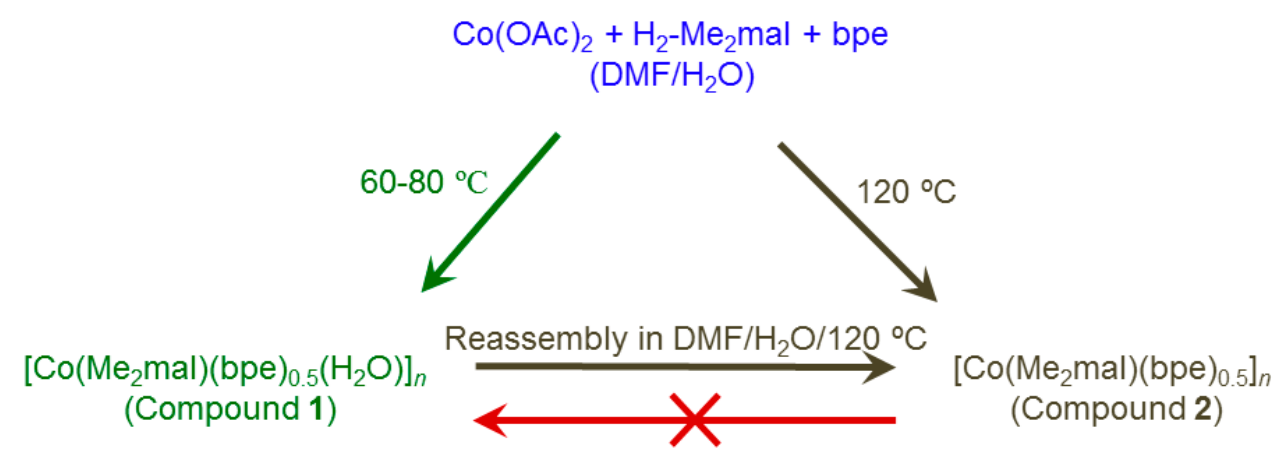

Scheme 1. The Schematic representation of the temperature-controlled assembly/reassembly of compounds 1 and 2.

The phase purity for the bulk samples of $\mathbf{1}, \mathbf{2}$, and the products obtained by the crystal reassembly of 2 was confirmed by PXRD (Figures S1 and S2 in Supporting Information) and by elemental analysis. The thermal stabilities of compounds $\mathbf{1}$ and $\mathbf{2}$ were also examined by TG analysis (Figure S3). The TGA curve for compound $\mathbf{1}$ showed consecutive weight loss steps at temperatures above $120{ }^{\circ} \mathrm{C}$, which corresponded to the gradual removal of one coordinated water molecule (found: $6.28 \%$; calcd: $6.04 \%$ ). At temperatures above $250^{\circ} \mathrm{C}$, the host framework underwent a rapid weight loss, which was attributed to the elimination of the organic ligands and the gradual decomposition of the compound. 
Compound 2 showed one large weight loss at temperatures above $300{ }^{\circ} \mathrm{C}$, corresponding to the elimination of the organic ligands, followed by the decomposition of the host framework.

\subsection{Description of the Structure}

Crystal Structures of Compound 1

[Co(Me 2 mal)(bpe $\left.)_{0.5}\left(\mathrm{H}_{2} \mathrm{O}\right)\right]_{n}$ (1). An X-ray structural analysis showed that compound 1 crystallized in the monoclinic space group $P 21 / n$ and the asymmetric unit of 1 contains one crystallographically independent $\mathrm{Co}$ (II) center, one $\mathrm{Me}_{2} \mathrm{mal}^{2-}$ anion, one-half of a bpe ligand, and one coordinated water molecule. As depicted in Figure 1, the geometry of the Co(II) center is a distorted octahedron with a $\mathrm{CoO}_{5} \mathrm{~N}$ coordination sphere. The equatorial positions on the octahedron are occupied by four oxygen atoms $(\mathrm{O} 2, \mathrm{O} 3$, and their symmetrical equivalents) derived from three $\mathrm{Me}_{2} \mathrm{mal}^{2-}$ ligands, while one nitrogen atom (N1) from one bpe ligand and one oxygen atom (O6) of a terminal water molecule occupied the axial positions. The $\mathrm{Co}-\mathrm{O}$ bond lengths at the $\mathrm{Co}(\mathrm{II})$ vary from 2.0747(18)-2.124(19) $\AA$ and a Co-N bond length is 2.151(2) $\AA$, which falls in the range of values for typical octahedral $\mathrm{Co}$ (II) complexes [52,53]. The two carboxylate groups of the $\mathrm{Me}_{2} \mathrm{mal}^{2-}$ ligand adopt a syn-anti $\mu_{2}: \eta^{1}, \eta^{1}$-bridging mode (Scheme $2 a$ ), in which the Co(II) ion is chelated by each of one oxygen atoms ( $\mathrm{O} 2$ and $\mathrm{O} 3)$, and connects to two crystallographically equivalent $\mathrm{Co}$ (II) ions through each of the other two oxygen atoms (O1 and $\mathrm{O} 4)$. Thus, each $\mathrm{Co}(\mathrm{II})$ center is linked to four neighbors via three $\mathrm{Me}_{2} \mathrm{mal}^{2-}$ bridges and results in a corrugated $\mathrm{Co}-\mathrm{Me}_{2}$ mal layer that is located parallel to the ac crystal plane (Figure 2a). The two unique Co $\cdots$ Co distances in the layer spanned by the $\mathrm{Me}_{2} \mathrm{mal}^{2-}$ ligands are 5.478(1) and 5.258(1) $\AA$. The adjacent $\mathrm{Co}-\mathrm{Me}_{2}$ mal layers are further pillared through bis-monodentate bpe ligands leading to a pillared-layer 3D framework with 1D channels along the crystallographic $c$ axis (Figure 2b). Similar structures have been reported in previous studies [54-56]. The bpe ligands are positioned alternately above and below the layers, in a trans array with the dimethyl groups of the $\mathrm{Me}_{2} \mathrm{mal}^{2-}$ ligand. The bridging bpe ligands separate the $\mathrm{Co}(\mathrm{II})$ ions by $13.668(2) \AA$, where the shortest interlayer Co $\cdots$ Co distance is 9.911(2) $\AA$. The shortest distance of the centroid-centroid between the adjacent pyridyl rings of the bpe is $7.496(2) \AA$, which rules out any $\pi-\pi$ interaction in compound 1 . The shortest centroid-centroid distance between the adjacent pyridyl rings of the bpe ligand in compound 1 is $7.496(2) \AA$, which are considerably higher than the limit for $\pi-\pi$ interactions between pyridyl rings, thus indicating there are no $\pi-\pi$ interactions in compound 1 . The intralayer hydrogen bonds between the oxygen atoms of the $\mathrm{Me}_{2} \mathrm{mal}^{2-}$ ligand and the coordinated water molecule in $\mathbf{1}$ (2.704(3) and 2.768(3) $\mathrm{A}^{\circ}$ for $\mathrm{O} 6 \cdots \mathrm{O} 2$ and $\mathrm{O} 6 \cdots \mathrm{O} 3$ and $150.4(2)$ and $163.9(4)^{\circ}$ for $\mathrm{O} 6-\mathrm{H} 6 \mathrm{~A} \ldots \mathrm{O} 2$ and $\left.\mathrm{O} 6-\mathrm{H} 6 \mathrm{~B} \cdots \mathrm{O} 4\right)$ donate to the stabilization of the structure.

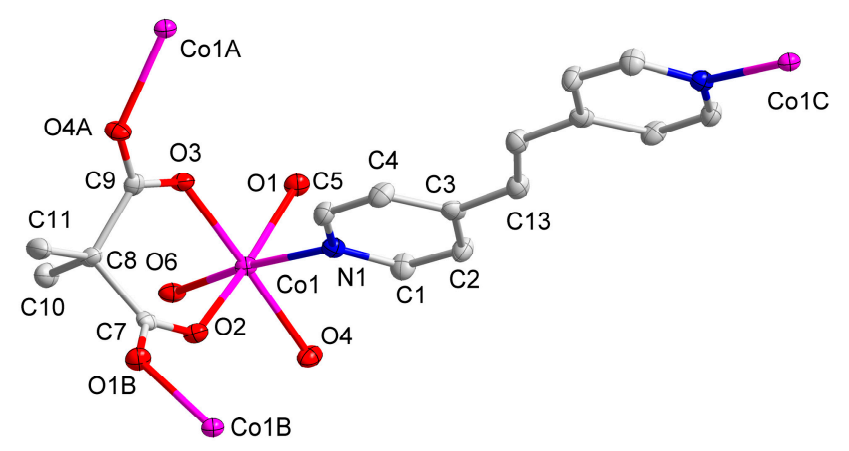

Figure 1. The metal coordination environments of compound 1. The $H$ atoms have been omitted for clarity. [Symmetry code: (A) $-0.5+\mathrm{x}, 1.5-\mathrm{y}, 0.5+\mathrm{z}$; (B) $0.5+\mathrm{x}, 1.5-\mathrm{y}, 0.5+\mathrm{z}$; (C) $1-\mathrm{x}, 2-\mathrm{y}, 3-\mathrm{z}$ ]. 
(a)<smiles>C[C@]1(C(=O)OCl)OCOC1=O</smiles>

(b)

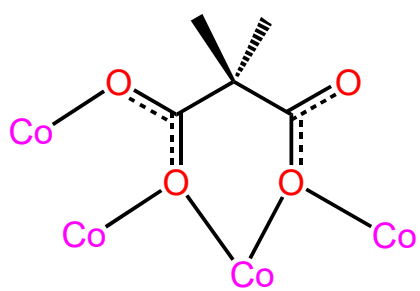

Scheme 2. The Schematic representations of (a) the symmetric $\mu_{3}: \eta^{1}, \eta^{1}, \eta^{1}, \eta^{1}$-bridging $\mathrm{Me}_{2} \mathrm{mal}^{2}$ ligand in compound 1 , and (b) the antisymmetric $\mu_{4}: \eta^{1}, \eta^{2}, \eta^{2}$-bridging $\mathrm{Me}_{2} \mathrm{mal}^{2-}$ ligand in compound 2.
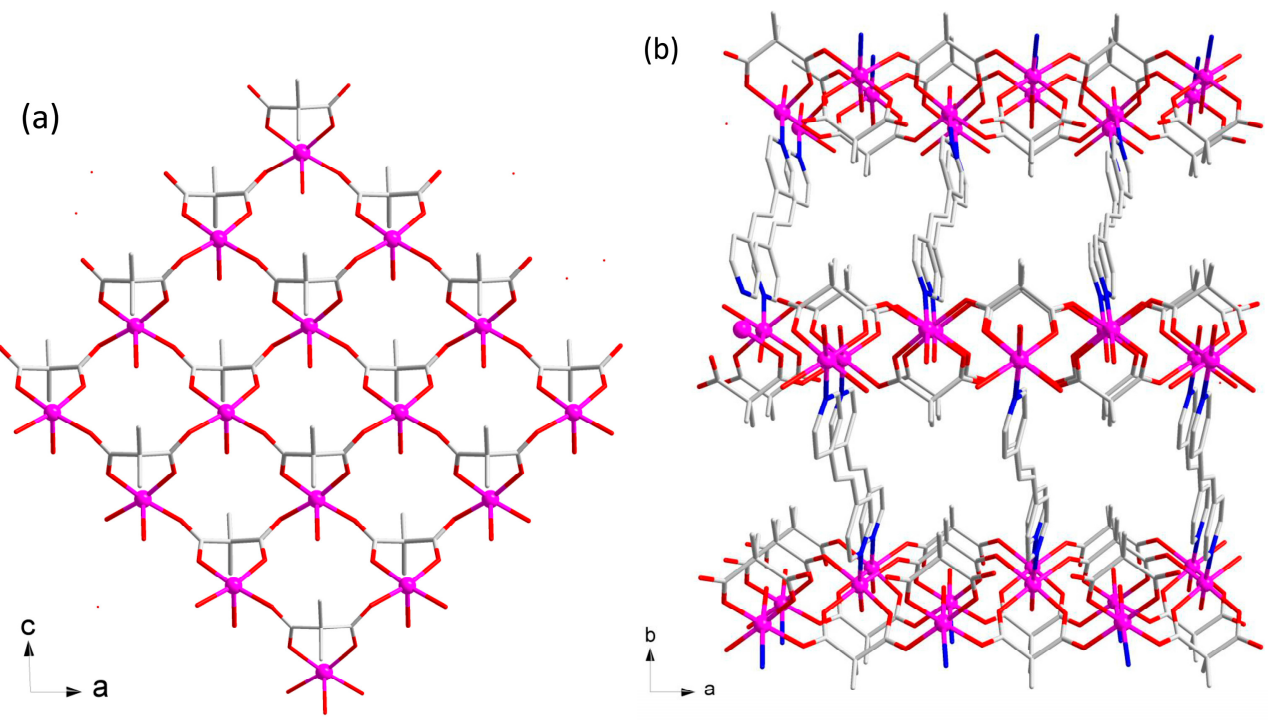

Figure 2. (a) View of the 2D layer of $\mathrm{Co}-\left(\mu_{3}-\mathrm{Me}_{2} \mathrm{mal}\right)$ in the crystallographic ac plane, $(\mathbf{b})$ view of the pillared-layer 3D structure of compound 1 with 1D channels along the $c$ axis. The $H$ atoms have been omitted for clarity.

Topological analysis of the 3D structure of compound 1 indicated that each Co(II) center with a $\mathrm{CoNO}_{5}$ coordination environment and $\mu_{3}-\mathrm{Me}_{2}$ mal can be viewed as a six-connected node and a three-connected node, respectively, while each bpe ligand that is bonded to two Co(II) centers can be treated as a two-connector. Such connectivity repeats in infinity, thus producing the Co-Me $\mathrm{mal}$ layer and the 3D framework of $\mathbf{1}$ as schematically represented in Figure 3. Analysis by the TOPOS software package showed that the framework of 1 could be explained as a binodal $(3,4)$-connected ins topology with the Schläfli symbol $\left(6^{3}\right)\left(6^{5} .8\right)$ [57].

(a)

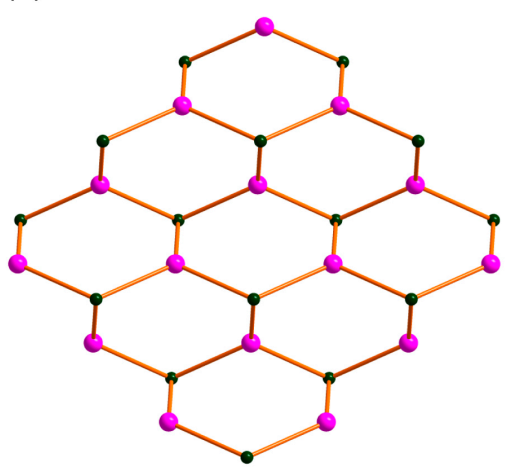

(b)

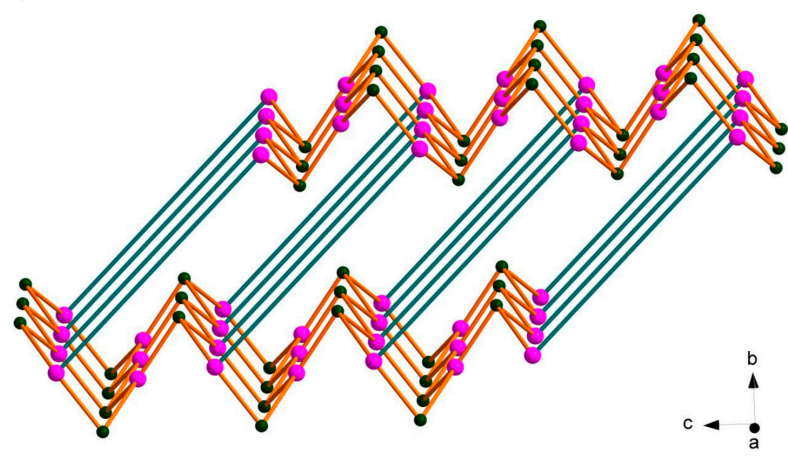

Figure 3. (a) View of the three-connected unimodal 2D net of the Co-Me $\mathrm{C}_{2}$ mal layer in $\mathbf{1}$ and (b) $(3,4)$-connected ins topology of compound 1. 
$\left[\mathrm{Co}\left(\mathrm{Me}_{2} \mathrm{mal}\right)(\mathrm{bpe})_{0.5}\right]_{n}$ (2). A single-crystal X-ray diffraction analysis reveals that 2 is a three-dimensional framework consisting of well-isolated one-dimensional cobalt/oxygen chains bridged by a bpe ligand along with a $\mathrm{Me}_{2}$ mal ligand. The asymmetric unit of compound 2 contains two $\mathrm{Co}(\mathrm{II})$ atoms at special positions, two $\mathrm{Me}_{2} \mathrm{mal}^{2-}$ groups, and one bpe ligand (Figure 4). The $\mathrm{Co} 1$ shows a distorted octahedral with a $\mathrm{CoO}_{4} \mathrm{~N}_{2}$ coordination sphere, where two oxygen atoms (O1, O1A) of the carboxylate from the two $\mathrm{Me}_{2} \mathrm{mal}^{2-}$ ligands and two nitrogen atoms (N1, N1A) from the two bpe ligands make up the equatorial plane, and the two carboxylate oxygen atoms $(\mathrm{O} 3, \mathrm{O} 3 \mathrm{~A})$ from two $\mathrm{Me}_{2} \mathrm{mal}^{2-}$ ligands occupy the axial positions. The $\mathrm{Co} 2$ center adopts a $\mathrm{CoO}_{6}$ distorted octahedral geometry bonded to six carboxylate oxygen atoms from four different $\mathrm{Me}_{2} \mathrm{mal}^{2-}$ ligands, where the four oxygen atoms $(\mathrm{O} 1, \mathrm{O} 2$, and their symmetric equivalents) occupy the equatorial plane and the two oxygen atoms, $\mathrm{O} 3$ and its symmetric equivalent, are coordinated to the axial positions. The $\mathrm{Co}-\mathrm{O}$ bond distances (ranging from 1.992(2)-2.163(2) $\AA$ ) and $\mathrm{Co}-\mathrm{N}(2.067(3) \AA)$ are all within the normal ranges for octahedral $\mathrm{Co}$ (II) complexes [42,43]. The $\mathrm{Me}_{2} \mathrm{mal}^{2-}$ ligand acts as an asymmetrical $\mu_{4}$-bridging ligand (Scheme 2b). One of two carboxylates in a $\mathrm{Me}_{2} \mathrm{mal}^{2-}$ adopt a anti, syn-syn, $\mu_{3}: \eta^{2}, \eta^{1}$-bridging mode with terminal bonding to the $\mathrm{Co} 2 \mathrm{~A}$ center through an $\mathrm{O} 2$ atom with the $\mathrm{Co} 1$ and $\mathrm{Co} 2$ centers bridged by the $\mathrm{O} 2$ atom, while the other one of two carboxylate groups show an anti,syn $\mu_{2}: \eta^{2}$-bridging mode that connects the $\mathrm{Co} 2$ to Co1A centers through its one carboxylate oxygen atom (O3) with an uncoordinated oxygen atom $(\mathrm{O} 4)$. Such an asymmetrical $\mu_{4}$-bridging structure was first obtained in the complex with malonate-related ligands. Therefore, the $\mathrm{Co} 1$ and $\mathrm{Co} 2$ centers are connected by one syn-syn carboxylate and two $\mu_{2}$-oxygen atoms derived from two carboxylate groups and lead to the formation of an edged-shared zigzag $\mathrm{Co}-\mathrm{Me}_{2}$ mal chain along the $c$ axis (Figure 5a). The intrachain Co1-Co2 bond distance is $3.150 \AA$, and the $\mathrm{Co} 1-\mathrm{O} 1-\mathrm{Co} 2$ and $\mathrm{Co} 1-\mathrm{O} 3-\mathrm{Co} 2$ bond angles are $95.35^{\circ}$ and $98.51^{\circ}$, respectively. The adjacent $\mathrm{Co}-\mathrm{Me}_{2}$ mal chains are further crosslinked through bis-monodentate bpe ligands leading to a 3D network structure with 3D channels (Figure 5b). In the crystal, the adjacent porous 3D framework is interpenetrated leading to a two-fold interpenetrated network, in which only the small 1D channels along the $a$ axis can be observed (Figure S4). In the 3D interpenetrated framework, the bridging bpe ligands separate the Co(II) ions by 13.287(4) $\AA$, where the shortest interchain Co $\cdots$ Co distance is 9.352(2) $\AA$. The shortest centroid-centroid distance between adjacent pyridyl rings of bpe is 7.496(2) $\AA$ ruling out any $\pi-\pi$ interactions in compound 2 .

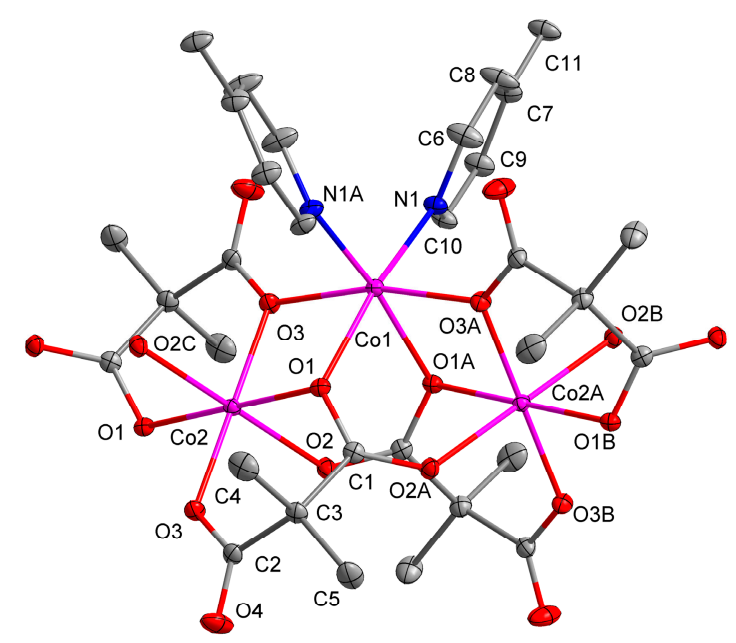

Figure 4. The metal coordination environments of compound 2. The $\mathrm{H}$ atoms have been omitted for clarity. [Symmetry code: (A) $1-\mathrm{x}, \mathrm{y}, 1.5-\mathrm{z}$; (B) $\mathrm{x}, 1-\mathrm{y},-0.5+\mathrm{z}$; (C) $1-\mathrm{x}, 1-\mathrm{y}, 2-\mathrm{z}$ ]. 
(a)

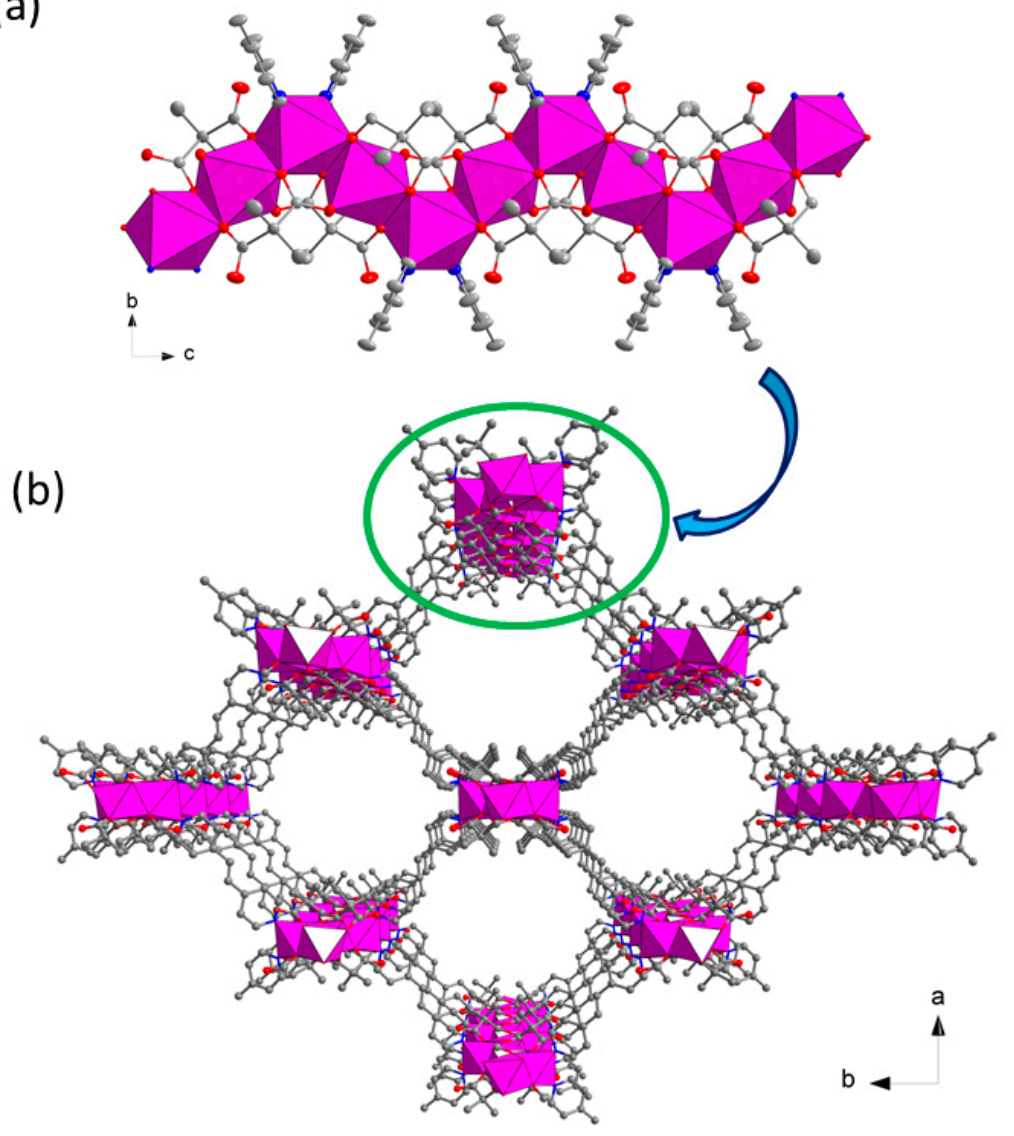

Figure 5. (a) View of the 1D edged-shared zigzag $\mathrm{Co}-\mathrm{Me}_{2}$ mal chain along the crystallographic $c$ axis; (b) view of the 3D porous structure of compound 2. The $\mathrm{H}$ atoms have been omitted for clarity.

\subsection{Magnetic Properties}

Solid-state, temperature-dependence of magnetic susceptibility data of compounds $\mathbf{1}$ and $\mathbf{2}$ were measured in the $2.0-300 \mathrm{~K}$ range under a $1.0 \mathrm{kOe}$ applied field.

The temperature dependence of $\chi_{M} T$ values of compound 1 is shown in Figure 6. The spin-only value at $300 \mathrm{~K}$ is $3.34 \mathrm{~cm}^{3} \mathrm{~K} \mathrm{~mol}^{-1}$, which is in agreement with that of the measured, calculated by a high-spin Co(II) ion with $S=3 / 2$ with a strong spin-orbit coupling [58]. The $\chi_{M} T$ value of 1 continues to decrease with cooling of the temperature from 300 to $10 \mathrm{~K}$, below $10 \mathrm{~K}$ the value of $\chi_{\mathrm{M}} T$ decreases more rapidly to $1.40 \mathrm{~cm}^{3} \mathrm{~K} \mathrm{~mol}^{-1}$ at $2.0 \mathrm{~K}$. The monotonic decrease in the $\chi_{\mathrm{M}} T$ value with decreasing temperatures are characteristics of overall antiferromagnetic interactions and/or spin-orbital couplings in compound 1 . Above $50 \mathrm{~K}$, the magnetic susceptibility data obeyed the Curie-Weiss law with a Curie constant $C=3.58 \mathrm{~cm}^{3} \mathrm{~mol}^{-1} \mathrm{~K}$ and Weiss $\theta=-23.15 \mathrm{~K}$ (Figure S5). The negative $\theta$ value indicates that antiferromagnetic coupling and the spin-orbital coupling existed in compound $\mathbf{1}$.

A plot of the temperature dependence of the $\chi_{M} T$ value for compound 2 is shown in Figure 7 . The $\chi_{\mathrm{M}} T$ value is $3.13 \mathrm{~cm}^{3} \mathrm{~K} \mathrm{~mol}^{-1}$ at $300 \mathrm{~K}$ which is significantly greater than the spin-only value for a the high-spin Co(II) center, while it is in agreement with the values observed of the magnetic moment for high-spin $\mathrm{Co}$ (II) complexes in an octahedral environment with strong spin-orbital coupling. The $\chi_{\mathrm{M}} T$ value decreases slowly to a minimum of $3.03 \mathrm{~cm}^{3} \mathrm{~K} \mathrm{~mol}^{-1}$ at $55 \mathrm{~K}$. Below $55 \mathrm{~K}$, the $\chi_{\mathrm{M}} T$ value sharply increases to reach a maximum of $9.12 \mathrm{~cm}^{3} \mathrm{~K} \mathrm{~mol}^{-1}$ at $2.0 \mathrm{~K}$, indicating the existence of the ferromagnetic interaction in compound 2 . The data of the temperature dependence of magnetic susceptibilities above $50 \mathrm{~K}$ followed the Curie-Weiss law giving a $\theta=-2.90 \mathrm{~K}$ and a $C=3.21 \mathrm{~cm}^{3} \mathrm{~K} \mathrm{~mol}^{-1}$ (Figure S6). The Curie constant of 2 was larger than the theoretical spin-only value of the Co(II) ion, indicating that an orbital contribution existed in compound 2 . Thereby, the weak and negative values of $\theta$ are unable to 
indicate the antiferromagnetic interaction between Co(II) centers in 2 because of the significant strong spin-orbital coupling of the octahedral $\mathrm{Co}(\mathrm{II})$ ions.

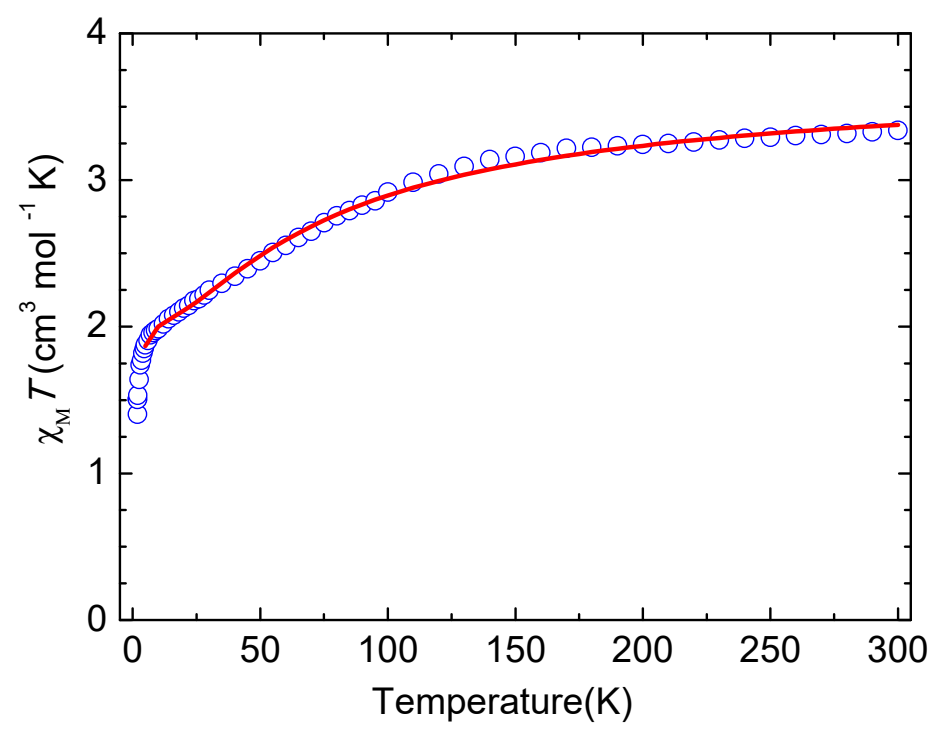

Figure 6. Plot of $\chi_{M} T$ vs. $T$ of compound 1 in an applied field of 1 kOe from 2 to $300 \mathrm{~K}$. The solid line represents the best fit.

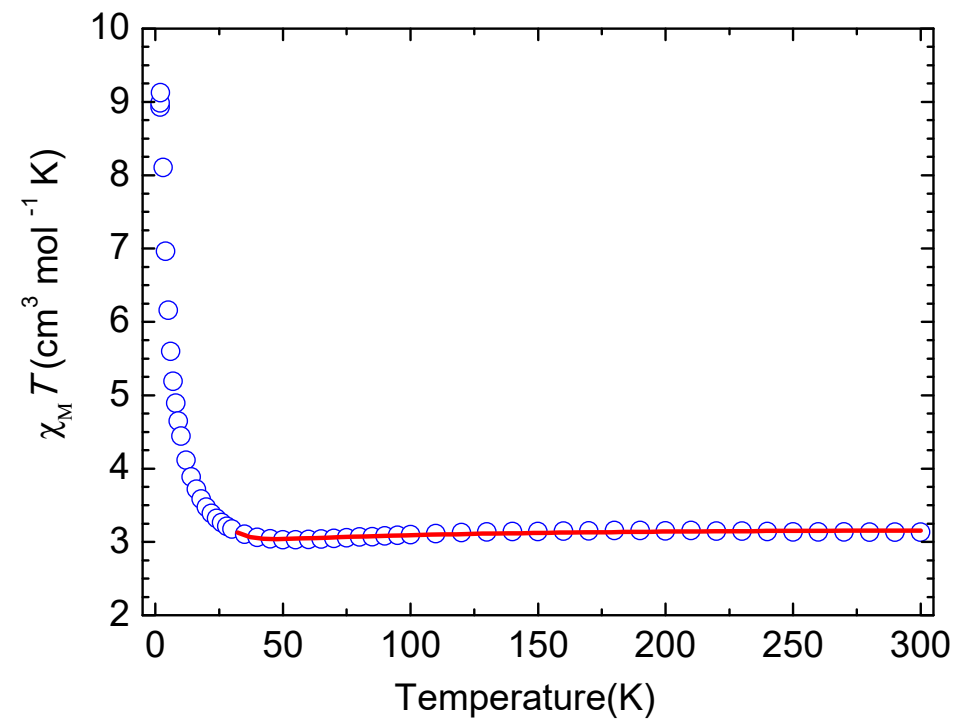

Figure 7. Plot of $\chi_{M} T$ vs. $T$ of compound 2 in an applied field of 1 kOe from 2 to $300 \mathrm{~K}$. The solid line represents the best fit.

Because of the contribution of the spin-orbit coupling for Co(II) ions, it is not possible to find a suitable analytical expression that describes the temperature-dependent magnetic susceptibility for $\mathrm{Co}$ (II) centers of the layered and chained polymeric structures in compounds $\mathbf{1}$ and $\mathbf{2}$, respectively. However, Rueff et al. successfully proposed a phenomenological approach for a low-dimensional polymeric $\mathrm{Co}$ (II) compound that permits the magnitude of the magnetic coupling and the spin-orbit coupling effects. They assumed the phenomenological equation [59]:

$$
\chi_{\mathrm{M}} T=A \exp \left(-E_{1} / k \mathrm{~T}\right)+B \exp \left(-E_{2} / k T\right)
$$

where $A+B$ are the Curie constants and the $E_{1}$ and $E_{2}$ are the activation energies, which correspond to the parameters of the spin-orbit coupling and the magnetic coupling interaction, respectively. The $E_{2}$ is 
related to the constant of the magnetic coupling $(J)$ according to the Ising chain approximation, $\chi_{\mathrm{M}} T \infty$ $\exp (+J / 2 k T)$. This equation sufficiently pronounces the spin-orbit coupling, which affects the splitting of the low-temperature divergence of the susceptibility between discrete levels and the exponential. Some reasonable values for magnetic interactions and interactions of spin-orbit coupling have been described in several studies on Co(II) coordination polymers with 1D and 2D structures [60-62].

The results obtained by the Rueff's procedure are quite consistent with the experimental data. For compound 1, the data above $10 \mathrm{~K}$ was fitted and the parameters of the fitting are $A+B=3.72 \mathrm{~cm}^{3} \mathrm{~K} \mathrm{~mol}^{-1}$, practically close to the Curie constant found from the Curie-Weiss law, $3.58 \mathrm{~cm}^{3} \mathrm{~K} \mathrm{~mol}^{-1}$. The $E_{1} / k$ was $+49.73 \mathrm{~K}$ which is in the same magnitude (the order of $+100 \mathrm{~K}$ ) to those reported for $\mathrm{Co}(\mathrm{II})$ compounds. Concerning the values obtained for antiferromagnetic exchange interactions, it is weak but significant $\left(E_{2} / k=0.46 \mathrm{~K}\right.$, corresponding to $\left.J=-0.92 \mathrm{~K}\right)$, which is in agreement with the antiferromagnetic property of compound 1 and consistent with some other reported 2D Co(II) compounds [61,62]. As described in the crystallographic part, compound $\mathbf{1}$ is comprised of $\mathrm{Co}$ (II) ions connected by carboxylate groups in a syn-anti bridging mode thus giving a $\mathrm{Co}-\mathrm{Me}_{2}$ mal layer, which is further linked in a three-dimensional network by bpe ligands. Thus, the overall antiferromagnetic exchange interaction can be attributed to magnetic interaction within the Co-carboxylate layer. Magnetic exchanges through the syn-anti carboxylate bridges for $\mathrm{Co}(\mathrm{II})$ and $\mathrm{Mn}$ (II) ions are usually reported as antiferromagnetic due to the good overlap of magnetic orbitals [54-56]. For compound 2, the data above $30 \mathrm{~K}$ were fitted and the best fit parameters of the $A+B$ value was $3.18 \mathrm{~cm}^{3} \mathrm{~K} \mathrm{~mol}^{-1}$, which is in good agreement with those reported in the literature for the Curie constant, $E_{1} / \mathrm{k}$, the effect of the distortion of coordination site and spin-orbit coupling, was $+99.41 \mathrm{~K}$ and $-E_{2} / \mathrm{k}$ was $4.07 \mathrm{~K}$, corresponding to magnetic interactions of $J=8.14 \mathrm{~K}$ within the Ising chain approximation, which is consistent with values reported for several 1D Co(II) complexes [59-61]. These fitting results indicate that the distinct ferromagnetic exchange is dominated between $\mathrm{Co}(\mathrm{II})$ through one $\mathrm{O}-\mathrm{C}-\mathrm{O}$ and two $\mu_{2}-\mathrm{O}$ bridges. The intrachain $\mathrm{Co} 1-\mathrm{O}-\mathrm{Co} 2$ angles and Co...Co distance are $98.5^{\circ}, 95.3^{\circ}$ and 3.150(1) $\AA$, respectively. Nevertheless, the shortest Co... Co distance in the chain is $9.352 \AA$. The magnetic interactions of compounds 1 and 2 can be compared to those of $\mathrm{Co}$ (II) compounds containing similar structures in the literature $[60,63]$, in which a weak antiferromagnetic interaction $(J=-1.30 \mathrm{~K})$ was dominated in a syn-anti carboxylate-bridged $\mathrm{Co}$ (II)-malonate layer and a weak ferromagnetic coupling $(\mathrm{J}=3.72 \mathrm{~K})$ was transmitted in a Co(II)-based chain with one $\mathrm{O}-\mathrm{C}-\mathrm{O}$ and two $\mu_{2}-\mathrm{O}$ bridges. This is in agreement with magneto-structural analyses: a small $\mathrm{Co}-\mathrm{O}-\mathrm{Co}$ angle resulting in a $\mathrm{Co}-\mathrm{Co}$ ferromagnetic coupling and a large $\mathrm{Co}-\mathrm{O}-\mathrm{Co}$ angle resulting in a $\mathrm{Co}-\mathrm{Co}$ antiferromagnetic interaction [63].

The ferromagnetic coupling of compound $\mathbf{2}$ was further estimated by isothermal magnetization data. As shown in Figure S7, the magnetization increased sharply and then reached a saturation plateau ( $2.53 \mathrm{~N} \beta$ at $7 \mathrm{~T}$ ) with a fast saturation of the magnetization. The fast saturated magnetization confirms the existence of ferromagnetic interactions within 2 and the saturation value was consistent with the theoretical values $(2-3 N \beta$ ) expected for $\mathrm{Co}(\mathrm{II})$ compounds. Indeed, no magnetic hysteresis loop was detected indicating the absence of magnetic ordering in 2 above $2.0 \mathrm{~K}$.

\section{Conclusions}

In summary, we report on the temperature-controlled synthesis and characterization of two new dicarboxylate-based 3D Co(II) coordination polymers. The formation of compound 1 was favored at lower temperatures of $60-80^{\circ} \mathrm{C}$, but a higher temperature of $120^{\circ} \mathrm{C}$ was favored to yield compound 2 . Indeed, a crystal reassembly from compound 1 to compound 2 was also observed by solvothermal treatment of 1 at $120{ }^{\circ} \mathrm{C}$ in $\mathrm{DMF} / \mathrm{H}_{2} \mathrm{O}$. The structure of compound 1 contains corrugated layers of $\mathrm{Co}$ (II) connected through syn-anti carboxylate bridges of $\mathrm{Me}_{2} \mathrm{mal}^{-}$ligands and bis-monodentate bpe pillars. Compound 2 shows a 3D porous framework involving one-dimensional Co-carboxylate chains connected by antisymmetric $\mu_{4}-\mathrm{Me}_{2} \mathrm{mal}^{2-}$ and bis-monodentate bpe ligands. Magnetic measurements indicate that antiferromagnetic interactions through the syn-anti carboxylate bridges of the $\mathrm{Me}_{2} \mathrm{mal}^{2-}$ ligands were dominated in compound 1, while compound 2 revealed ferromagnetic interactions 
resulting from the short Co-Co separation (3.150 $\AA$ ) and small Co-O-Co bridging angles $\left(98.5^{\circ}\right.$ and $95.3^{\circ}$ ) exchange pathway of the $\mu_{4}-\mathrm{Me}_{2} \mathrm{mal}^{2-}$ bridges. The studies demonstrate that dimethylmalonic acid has great substantial for use in the preparation of coordination polymers with multipurpose structural topologies and unusual magnetic properties.

Supplementary Materials: The following are available online at http://www.mdpi.com/2073-4360/11/5/795/s1, Figure S1: Simulated PXRD pattern (blue) and experimental PXRD pattern (red) of 1, Figure S2: (a) Simulated PXRD pattern (blue) and experimental PXRD pattern (red) of 2; (b) experimental PXRD patterns of 2 synthesized by method A (blue) and method B (red), Figure S3: Thermogravimetric (TG) analysis diagrams of 1 and 2, Figure S4: (a) The two-fold interpenetrated network of 2; (b) the 1D channels along the $a$ axis of 2, Figure S5: Plot of $\chi_{M}{ }^{-1}$ (cycle) vs. temperature for a microcrystalline sample of compound 1 . The solid line represents the best fit $\chi_{M}{ }^{-1}$ above $50 \mathrm{~K}$ with a Curie-Weiss law, Figure S6: Plot of $\chi_{\mathrm{M}}{ }^{-1}$ (cycle) vs. temperature for a microcrystalline sample of compound 2. The solid line represents the best fit $\chi_{\mathrm{M}}{ }^{-1}$ above $50 \mathrm{~K}$ with a Curie-Weiss law, Figure S7: Field dependence of magnetizations of compound 2 at $2.0 \mathrm{~K}$.

Author Contributions: C.-I.Y. conceived, designed the experiments, and wrote the paper; S.-S.D. and C.-H.L. performed the experiments.

Acknowledgments: The authors gratefully acknowledge financial support for this work from the Tunghai University, and the Ministry of Science and Technology of Taiwan (MOST 106-2113-M-029-008). We also thank the instrumental supporting and measuring by Tsai Hui-lien and Min Kai Lee at the National Cheng Kung University.

Conflicts of Interest: The authors declare no conflict of interest.

\section{References}

1. Eddaoudi, M.; Kim, J.; Rosi, N.; Vodak, D.; Wachter, J.; O’Keeffe, M.; Yaghi, O.M. Systematic design of pore size and functionality in isoreticular MOFs and their application in methane storage. Science 2002, 295, 469-472. [CrossRef] [PubMed]

2. Kitagawa, S.; Kitaura, R.; Noro, S. Functional porous coordination polymers. Angew. Chem. Int. Ed. 2004, 43, 2334-2375. [CrossRef]

3. Ferey, G.; Mellot-Draznieks, C.; Serre, C.; Millange, F. Crystallized frameworks with giant pores: Are there limits to the possible? Acc. Chem. Res. 2005, 38, 217-225. [CrossRef] [PubMed]

4. Xiang, S.; Wu, X.; Zhang, J.; Fu, R.; Hu, S.; Zhang, X. 3D Canted Antiferromagnetic Porous Metal-Organic Framework with Anatase Topology through Assembly of an Analogue of Polyoxometalate. J. Am. Chem. Soc. 2005, 127, 16352-16353. [CrossRef]

5. Ockwig, N.W.; Delgado-Friedrichs, O.; O'Keeffe, M.; Yaghi, O.M. Reticular chemistry: Occurrence and taxonomy of nets and grammar for the design of frameworks. Acc. Chem. Res. 2005, 38, 176-182. [CrossRef] [PubMed]

6. Ferey, G. Hybrid porous solids: Past, present, future. Chem. Soc. Rev. 2008, 37, 191-214. [CrossRef]

7. Moulton, B.; Zaworotko, M.J. From Molecules to Crystal Engineering: Supramolecular Isomerism and Polymorphism in Network Solids. Chem. Rev. 2001, 101, 1629-1658. [CrossRef] [PubMed]

8. Welte, L.; Calzolari, A.; Di Felice, R.; Zamora, F.; Gomez-Herrero, J. Highly conductive self-assembled nanoribbons of coordination polymers. Nat. Nanotechnol. 2010, 5, 110-115. [CrossRef] [PubMed]

9. Barth, J.V.; Costantini, G.; Kern, K. Engineering atomic and molecular nanostructures at surfaces. Nature 2005, 437, 671-679. [CrossRef] [PubMed]

10. Guijarro, A.; Castillo, O.; Welte, L.; Calzolari, A.; Miguel, P.J.S.; Gómez-García, C.J.; Olea, D.; di Felice, R.; Gómez-Herrero, J.; Zamora, F. Conductive Nanostructures of MMX Chains. Adv. Funct. Mater. 2010, 20, 1451-1457. [CrossRef]

11. Coronado, E.; Minguez Espallargas, G. Dynamic magnetic MOFs. Chem. Soc. Rev. 2013, 42, 1525-1539. [CrossRef] [PubMed]

12. Chaemchuen, S.; Kabir, N.A.; Zhou, K.; Verpoort, F. Metal-organic frameworks for upgrading biogas via $\mathrm{CO}_{2}$ adsorption to biogas green energy. Chem. Soc. Rev. 2013, 42, 9304. [CrossRef] [PubMed]

13. Yoon, J.; Solomon, E.I. Electronic structures of exchange coupled trigonal trimeric Cu(II) complexes: Spin frustration, antisymmetric exchange, pseudo-A terms, and their relation to $\mathrm{O} 2$ activation in the multicopper oxidases. Coordin. Chem. Rev. 2007, 251,379-400. [CrossRef] 
14. Zhang, Q.; Li, B.; Chen, L. First-Principles Study of Microporous Magnets M-MOF-74 (M = Ni, Co, Fe, Mn): The Role of Metal Centers. Inorg. Chem. 2013, 52, 9356-9362. [CrossRef] [PubMed]

15. Saitoh, A.; Miyasaka, H.; Yamashita, M.; Clérac, R. Direct evidence of exchange interaction dependence of magnetization relaxation in a family of ferromagnetic-type single-chain magnets. J. Mater. Chem. 2007, 17, 2002-2012. [CrossRef]

16. Dhakshinamoorthy, A.; Li, Z.; Garcia, H. Catalysis and photocatalysis by metal organic frameworks. Chem. Soc. Rev. 2018, 47, 8134-8172. [CrossRef]

17. Dhakshinamoorthy, A.; Asiri, A.M.; Garcia, H. Formation of C-C and C-Heteroatom Bonds by C-H Activation by Metal Organic Frameworks as Catalysts or Supports. ACS Catal. 2018, 9, 1081-1102. [CrossRef]

18. Dhakshinamoorthy, A.; Santiago-Portillo, A.; Asiri, A.M.; Garcia, H. Engineering UiO-66 Metal Organic Framework for Heterogeneous Catalysis. ChemCatChem 2019, 11, 899-923. [CrossRef]

19. Kurmoo, M. Magnetic metal-organic frameworks. Chem. Soc. Rev. 2009, 38, 1353-1379. [CrossRef]

20. Zeng, Y.F.; Hu, X.; Liu, F.C.; Bu, X.H. Azido-mediated systems showing different magnetic behaviors. Chem. Soc. Rev. 2009, 38, 469-480. [CrossRef]

21. Gatteschi, D.; Kahn, O.; Miller, J.S.; Palacio, F. Magnetic Molecular Materials; Kluwer Academic: Dordrecht, The Netherlands, 1991.

22. Willet, R.D.; Gatteschi, D.; Kahn, O. Magneto-Structural Correlations in Exchange Coupled Systems; Reidel Publishing: Dordrecht, The Netherlands, 1985.

23. Weng, D.F.; Wang, Z.M.; Gao, S. Framework-structured weak ferromagnets. Chem. Soc. Rev. 2011, 40, 3157-3181. [CrossRef]

24. Wang, X.P.; Chen, W.M.; Qi, H.; Li, X.Y.; Rajnak, C.; Feng, Z.Y.; Kurmoo, M.; Boca, R.; Jia, C.J.; Tung, C.H.; et al. Solvent-Controlled Phase Transition of a Co(II)-Organic Framework: From Achiral to Chiral and Two to Three Dimensions. Chemistry 2017, 23, 7990-7996. [CrossRef] [PubMed]

25. Ma, R.; Chen, Z.; Cao, F.; Wang, S.; Huang, X.; Li, Y.; Lu, J.; Li, D.; Dou, J. Two 2-D multifunctional cobalt(ii) compounds: Field-induced single-ion magnetism and catalytic oxidation of benzylic C-H bonds. Dalton Trans. 2017, 46, 2137-2145. [CrossRef]

26. Zheng, T.; Ren, M.; Bao, S.-S.; Zheng, L.-M. M2(pbtcH)(phen)2(H2O)2 [M(II)=Co, Ni]: Mixed-ligated metal phosphonates based on 5-phosphonatophenyl-1,2,4-tricarboxylic acid showing double chain structures. Chin. Chem. Lett. 2014, 25, 835-838. [CrossRef]

27. Wang, S.; Cao, T.; Yan, H.; Li, Y.; Lu, J.; Ma, R.; Li, D.; Dou, J.; Bai, J. Functionalization of Microporous Lanthanide-Based Metal-Organic Frameworks by Dicarboxylate Ligands with Methyl-Substituted Thieno[2,3-b]thiophene Groups: Sensing Activities and Magnetic Properties. Inorg. Chem. 2016, 55, 5139-5151. [CrossRef]

28. Liu, Y.N.; Su, H.F.; Li, Y.W.; Liu, Q.Y.; Jaglicic, Z.; Wang, W.G.; Tung, C.H.; Sun, D. Space Craft-like Octanuclear Co(II)-Silsesquioxane Nanocages: Synthesis, Structure, Magnetic Properties, Solution Behavior, and Catalytic Activity for Hydroboration of Ketones. Inorg Chem 2019, 58, 4574-4582. [CrossRef]

29. Chen, Z.; Yin, L.; Mi, X.; Wang, S.; Cao, F.; Wang, Z.; Li, Y.; Lu, J.; Dou, J. Field-induced slow magnetic relaxation of two 1-D compounds containing six-coordinated cobalt(ii) ions: Influence of the coordination geometry. Inorg. Chem. Front. 2018, 5, 2314-2320. [CrossRef]

30. De Munno, G.; Viterbo, D.; Caneschi, A.; Lloret, F.; Julve, M. A Giant Antiferromagnetic Interaction through the Bihydroxide Bridge (H3O2-). Inorg. Chem. 1994, 33, 1585-1586. [CrossRef]

31. Kar, P.; Drew, M.G.; Gomez-Garcia, C.J.; Ghosh, A. Coordination polymers containing manganese(II)-azido layers connected by dipyridyl-tetrazine and 4,4'-azobis(pyridine) linkers. Inorg. Chem. 2013, 52, 1640-1649. [CrossRef]

32. Cheng, X.N.; Xue, W.; Huang, J.H.; Chen, X.M. Spin canting and/or metamagnetic behaviours of four isostructural grid-type coordination networks. Dalton. Trans. 2009, 5701-5707. [CrossRef]

33. De Munno, G.; Poerio, T.; Julve, M.; Lloret, F.; Faus, J.; Caneschi, A. Syntheses, crystal structures and magnetic properties of one-, two- and three-dimensional 2,2'-bipyrimidine-containing copper(II) complexes. J. Chem. Soc. Dalton Trans. 1998, 1679-1686. [CrossRef]

34. Okawa, H.; Shigematsu, A.; Sadakiyo, M.; Miyagawa, T.; Yoneda, K.; Ohba, M.; Kitagawa, H. Oxalate-bridged bimetallic complexes $\{\mathrm{NH}($ prol)3\}[MCr(ox)3] (M = Mn(II), Fe(II), Co(II); NH(prol)3(+) = tri(3-hydroxypropyl)ammonium) exhibiting coexistent ferromagnetism and proton conduction. J. Am. Chem. Soc. 2009, 131, 13516-13522. [CrossRef] 
35. Toma, L.M.; Ruiz-Perez, C.; Pasan, J.; Wernsdorfer, W.; Lloret, F.; Julve, M. Molecular engineering to control the magnetic interaction between single-chain magnets assembled in a two-dimensional network. J. Am. Chem. Soc. 2012, 134, 15265-15268. [CrossRef]

36. Miyasaka, H. Control of charge transfer in donor/acceptor metal-organic frameworks. Acc. Chem. Res. 2013, 46, 248-257. [CrossRef]

37. Yang, T.; Cui, H.; Zhang, C.; Zhang, L.; Su, C.Y. Porous metal-organic framework catalyzing the three-component coupling of sulfonyl azide, alkyne, and amine. Inorg. Chem. 2013, 52, 9053-9059. [CrossRef]

38. Lin, R.B.; Chen, D.; Lin, Y.Y.; Zhang, J.P.; Chen, X.M. A zeolite-like zinc triazolate framework with high gas adsorption and separation performance. Inorg. Chem. 2012, 51, 9950-9955. [CrossRef]

39. Wriedt, M.; Yakovenko, A.A.; Halder, G.J.; Prosvirin, A.V.; Dunbar, K.R.; Zhou, H.C. Reversible switching from antiferro- to ferromagnetic behavior by solvent-mediated, thermally-induced phase transitions in a trimorphic MOF-based magnetic sponge system. J. Am. Chem. Soc. 2013, 135, 4040-4050. [CrossRef]

40. Zeng, M.H.; Feng, X.L.; Chen, X.M. Crystal-to-crystal transformations of a microporous metal-organic laminated framework triggered by guest exchange, dehydration and readsorption. Dalton Trans. 2004, 2217-2223. [CrossRef]

41. Choi, H.J.; Suh, M.P. Dynamic and redox active pillared bilayer open framework: Single-crystal-to-single-crystal transformations upon guest removal, guest exchange, and framework oxidation. J. Am. Chem. Soc. 2004, 126, 15844-15851. [CrossRef]

42. Chen, C.L.; Goforth, A.M.; Smith, M.D.; Su, C.Y.; zur Loye, H.C. $\left[\mathrm{Co}_{2}(\text { ppca })_{2}\left(\mathrm{H}_{2} \mathrm{O}\right)\left(\mathrm{V}_{4} \mathrm{O}_{12}\right)_{0.5}\right]$ : A framework material exhibiting reversible shrinkage and expansion through a single-crystal-to-single-crystal transformation involving a change in the cobalt coordination environment. Angew. Chem. Int. Ed. 2005, 44, 6673-6677. [CrossRef] [PubMed]

43. Hu, C.; Englert, U. Crystal-to-crystal transformation from a chain polymer to a two-dimensional network at low temperatures. Angew. Chem. Int. Ed. 2005, 44, 2281-2283. [CrossRef] [PubMed]

44. Wang, P.; Moorefield, C.N.; Panzner, M.; Newkome, G.R. TerpyridineCuIIPolycarboxylate Crystal Reorganization to One- and Two-Dimensional Nanostructures: Crystal Disassembly and Reassembly. Cryst. Growth Des. 2006, 6, 1563-1565. [CrossRef]

45. Sheldrick, G.M. Program for the Refinement of Crystal Structures; University of Göttingen: Göttingen, Germany, 1993.

46. Sheldrick, G.M. SHELXL2014; University of Goëttingen: Goëttingen, Germany, 2014.

47. Mulay, L.N.; Boudreaux, E.A. Theory and Applications of Molecular Diamagnetism; Wiley-VCH: New York, NY, USA, 1976; pp. 491-494.

48. Kang, X.M.; Wang, W.M.; Yao, L.H.; Ren, H.X.; Zhao, B. Solvent-dependent variations of both structure and catalytic performance in three manganese coordination polymers. Dalton Trans. 2018, 47, 6986-6994. [CrossRef] [PubMed]

49. Tripathi, S.; Srirambalaji, R.; Patra, S.; Anantharaman, G. Anion triggered and solvent assisted structural diversity and reversible single-crystal-to-single-crystal (SCSC) transformation between 1D and 2D coordination polymers. CrystEngComm 2015, 17, 8876-8887. [CrossRef]

50. Schneemann, A.; Bon, V.; Schwedler, I.; Senkovska, I.; Kaskel, S.; Fischer, R.A. Flexible metal-organic frameworks. Chem. Soc. Rev. 2014, 43, 6062-6096. [CrossRef]

51. Liu, Y.-H.; Lee, S.-H.; Chiang, J.-C.; Chen, P.-C.; Chien, P.-H.; Yang, C.-I. Dehydration induced 2D-to-3D crystal-to-crystal network re-assembly and ferromagnetism tuning within two chiral copper(II)-tartrate coordination polymers. Dalton Trans. 2013, 42, 16857-16867. [CrossRef]

52. Tsao, J.Y.; Tsai, J.D.; Yang, C.I. Azide-bridged Cu(ii), Mn(ii) and Co(ii) coordination polymers constructed with a bifunctional ligand of 6-(1H-tetrazol-5-yl)-2,2'-bipyridine. Dalton Trans. 2016, 45, 3388-3397. [CrossRef] [PubMed]

53. Zhang, Z.-Z.; Chang, H.-T.; Kuo, Y.; Lee, G.-H.; Yang, C.-I. Two New Three-Dimensional Pillared-Layer $\mathrm{Co}(\mathrm{II})$ and $\mathrm{Cu}(\mathrm{II})$ Frameworks Involving a [M2(EO-N3)2] Motif from a Semi-Flexible N-Donor Ligand, 5,5'-Bipyrimidin: Syntheses, Structures and Magnetic Properties. Polymers 2018, 10, 229. [CrossRef] [PubMed]

54. Nagaraja, C.M.; Haldar, R.; Maji, T.K.; Rao, C.N.R. Chiral Porous Metal-Organic Frameworks of Co(II) and $\mathrm{Ni}(\mathrm{II})$ : Synthesis, Structure, Magnetic Properties, and $\mathrm{CO}_{2}$ Uptake. Inorg. Chem. 2012, 12, 975-981. [CrossRef] 
55. Rodríguez-Martín, Y.; Hernández-Molina, M.; Sanchiz, J.; Ruiz-Pérez, C.; Lloret, F.; Julve, M. Crystal structures and magnetic properties of two- and three-dimensional malonato-bridged manganese(ii) complexes. Dalton Trans. 2003, 2359-2365. [CrossRef]

56. Déniz, M.; Hernández-Rodríguez, I.; Pasán,J.; Fabelo, O.; Cañadillas-Delgado, L.; Yuste, C.; Julve, M.; Lloret, F.; Ruiz-Pérez, C. Pillaring Role of 4,4' -Azobis(pyridine) in Substituted Malonate-Containing Manganese(II) Complexes: Syntheses, Crystal Structures, and Magnetic Properties. Cryst. Growth Des. 2012, 12, 4505-4518. [CrossRef]

57. O'Keeffe, M.; Peskov, M.A.; Ramsden, S.J.; Yaghi, O.M. The Reticular Chemistry Structure Resource (RCSR) Database of, and Symbols for, Crystal Nets. Acc. Chem. Res. 2008, 41, 1782-1789. [CrossRef]

58. Zeng, M.H.; Wu, M.C.; Liang, H.; Zhou, Y.L.; Chen, X.M.; Ng, S.W. 3D homometallic carboxylate ferrimagnet constructed from a manganese(II) succinate carboxylate layer motif pillared by isonicotinate spacers. Inorg. Chem. 2007, 46, 7241-7243. [CrossRef] [PubMed]

59. Rueff, J.-M.; Masciocchi, N.; Rabu, P.; Sironi, A.; Skoulios, A. Synthesis, Structure and Magnetism of Homologous Series of Polycrystalline Cobalt Alkane Mono- and Dicarboxylate Soaps. Chem. Eur. J. 2002, 8. [CrossRef]

60. Huang, F.-P.; Li, H.-Y.; Yu, Q.; Bian, H.-D.; Tian, J.-L.; Yan, S.-P.; Liao, D.-Z.; Cheng, P. Co(ii)/Ni(ii) coordination polymers incorporated with a bent connector: Crystal structures and magnetic properties. CrystEngComm 2012, 14, 4756-4766. [CrossRef]

61. Beghidja, A.; Rogez, G.; Rabu, P.; Welter, R.; Drillon, M. An approach to chiral magnets using $\alpha$-hydroxycarboxylates. J. Mater. Chem. 2006, 16, 2715-2728. [CrossRef]

62. Boonmak, J.; Nakanob, M.; Youngme, S. Structural diversity and magnetic properties in 1D and 2D azido-bridged cobalt(II) complexes with 1,2-bis(2-pyridyl)ethylene. Dalton Trans. 2011, 40, 1254-1260. [CrossRef]

63. Fabelo, O.; Canadillas-Delgado, L.; Pasan, J.; Delgado, F.S.; Lloret, F.; Cano, J.; Julve, M.; Ruiz-Perez, C. Study of the influence of the bridge on the magnetic coupling in cobalt(II) complexes. Inorg. Chem. 2009, 48, 11342-11351. [CrossRef] 